\title{
Acesso da criança na atenção primária à saúde: uma revisão integrativa
}

\author{
Child access to primary health care: an integrative review \\ Acceso infantil a la atención primaria de salud: una revisión integrativa
}

\begin{abstract}
RESUMO
Objetivo: Analisar os fatores relacionados a garantia do acesso de crianças na atenção primária à saúde. Método: Trata-se de uma revisão integrativa da literatura realizada a partir das bases de dados ScIELO, LILACS e BDENF. Para a definição da pergunta norteadora utilizou-se a estratégia PICO e quanto ao processo de seleção dos estudos, utilizou-se o fluxograma PRISMA. As buscas abrangeram o período de 2014 a 2019, sendo selecionados os artigos disponíveis em português, na íntegra e no formato original. Resultados: Identificou-se barreiras relacionadas ao acesso, principalmente organizacional, e fragilidades na articulação entre os diferentes niveis e locais de prestação de serviços. Conclusão: Faz-se necessário uma atuação de modo multiprofissional com a participação ativa do enfermeiro. Além disso, entende-se que precisa existir vínculo empático, longitudinal e integral entre os profissionais de saúde e as famílias.
\end{abstract}

DESCRITORES: Acesso aos Serviços de Saúde; Cuidado da Criança; Atenção Primária à Saúde.

\section{ABSTRACT}

Objective: To analyze factors related to ensuring children's access to primary health care. Method: This is an integrative literature review based on the databases SCIELO, LILACS and BDENF. For the definition of the guiding question the PICO strategy was used and for the study selection process, the PRISMA flowchart was used. The searches covered the period from 2014 to 2019, being selected the articles available in Portuguese, in full and in original format. Results: We identified barriers related to access, especially organizational, and weaknesses in the articulation between different levels and locations of service delivery. Conclusion: It is necessary to act in a multidisciplinary way with the active participation of nurses. In addition, it is understood that there must be an empathic, longitudinal and integral bond between health professionals and families.

ESCRIPTORS: Health Services Accessibility; Child Care; Primary Health Care.

\section{RESUMEN}

Objetivo: Analizar los factores relacionados con garantizar el acceso de los niños a la atención primaria de salud. Método: Esta es una revisión de literatura integradora basada en las bases de datos ScIELO, LILACS y BDENF. Para la definición de la pregunta guía se utilizó la estrategia PICO y para el proceso de selección del estudio, se utilizó el diagrama de flujo PRISMA. Las búsquedas abarcaron el período de 2014 a 2019, seleccionándose los artículos disponibles en portugués, en su totalidad y en formato original. Resultados: Identificamos barreras relacionadas con el acceso, especialmente organizacionales, y debilidades en la articulación entre diferentes niveles y ubicaciones de prestación de servicios. Conclusión: Es necesario actuar de manera multidisciplinaria con la participación activa de las enfermeras. Además, se entiende que debe existir un vínculo empático, longitudinal e integral entre los profesionales de la salud y las familias.

DESCRIPTORES: Accesibilidad a los Servicios de Salud; Cuidado del Niño; Atención Primaria de Salud.

RECEBIDO EM: 09/07/2020 APROVADO EM: 25/10/2020

\section{Adeniane Marques Ribeiro Ascenso}

Enfermeira. Universidade Paulista (UNIP), Campus Brasília, Distrito Federal, Brasil.

ORCID: 0000-0003-1693-2120

\section{Ricardo Saraiva Aguiar}

Professor Assistente. Curso de Graduação em Enfermagem, Universidade Paulista (UNIP), Campus Brasília, Distrito Federal, Brasil.

ORCID: 0000-0003-0335-2194 


\section{INTRODUÇÃO}

A atenção à saúde da criança vem passando por transformações em função da mudança de perfil epidemiológico, dos avanços científicos, da incorporação de tecnologias e da constante mudança nos modelos assistenciais. Todavia, apesar desse cuidado buscar promover o acompanhamento sistemático do crescimento e desenvolvimento, ainda é possível se deparar com uma assistência descoordenada e com ações fragmentadas e pouco resolutivas frente às demandas de saúde da criança e sua família ${ }^{1}$.

Muitos esforços mundiais têm sido empregados para melhorar as condições de saúde dessa população com o objetivo de reduzir a morbidade e mortalidade na infância. Para a Organização Mundial da Saúde (OMS), a saúde infantil é a prioridade central do desenvolvimento humano, que requer esforços para a redução da mortalidade na perspectiva do acesso e cobertura universal em saúde ${ }^{2}$.

Diante disso, a Estratégia Saúde da Família (ESF), no contexto do cuidado infantil, mostra-se como um importante espaço de promoção da aproximação entre equipe de saúde e cuidador/família por entrelaçar possibilidades de acesso aos serviços e aos cuidados efetivos e eficazes para a manutenção da saúde da criança $a^{2-3}$.

A atenção primária à saúde (APS) deve representar o primeiro nível de acesso dos usuários ao sistema de saúde e deve desenvolver ações de prevenção de riscos, agravos e doenças e de promoção, proteção, cura e reabilitação da saúde, visando ao atendimento das demandas de saúde dos indivíduos, das famílias e das comunidades ${ }^{3-4}$.

Desse modo, a APS precisa ser fortalecida para possibilitar a ampliação da produção de cuidado com base na articulação de tecnologias relacionais, como vínculo, humanização, respeito e corresponsabilização, com tecnologias de promoção, prevenção e assistência, de modo a resultar em uma maior qualificação da atenção à saúde, tanto da criança como de toda comunidade 5 .
Muitos esforços

mundiais têm

sido empregados

para melhorar as

condições de saúde

dessa população

com o objetivo de

reduzir a morbidade

e mortalidade

na infância. Para

a Organização

Mundial da

Saúde (OMS), a

saúde infantil é a

prioridade central

do desenvolvimento

humano, que

requer esforços

para a redução da

mortalidade na

perspectiva do acesso

e cobertura universal

em saúde.
Portanto, o presente estudo tem como objetivo analisar os fatores relacionados a garantia do acesso de crianças na APS. Sob essa perspectiva, destaca-se a questão que norteou a presente proposta investigativa: quais os fatores relacionados ao acesso da criança aos serviços disponíveis na APS?

\section{MÉTODOS}

Trata-se de uma revisão integrativa da literatura, uma vez que contribui no processamento sistemático e analítico dos resultados, pois é característica da busca de informações sobre um assunto ou tema que resuma a situação da ciência sobre um problema de pesquisa, visando a clareza do determinado tema ${ }^{6}$.

Elaborou-se, na primeira fase, a pergunta norteadora de pesquisa. Para a construção dessa, utilizou-se da estratégia PICO: $\mathrm{P}$ - população e problema; I - intervenção; C - comparação; e O - outcome (termo em inglês que significa desfecho $)^{7}$. Assim, considerou-se P: pacientes crianças; I: acesso aos serviços de saúde; C: qualquer comparação relacionada ao acesso; O: serviços disponíveis na APS. Nesta direção, a pergunta construída foi: quais os fatores relacionados ao acesso da criança aos serviços disponíveis na APS?

Construiu-se para a segunda fase, uma estratégia de busca por dois revisores independentes utilizando os descritores acesso aos serviços de saúde, cuidado da criança e atenção primária à saúde nas bases de dados eletrônicas Scientific Electronic Library Online (SciELO), Literatura Científica e Técnica da América Latina e Caribe (LILACS) e Base de Dados em Enfermagem (BDENF).

Refinou-se, contemplando a terceira fase da pesquisa com a aplicação dos critérios de inclusão previamente estabelecidos na estratégia de busca: artigos publicados de forma online nos últimos 6 anos (2014 a 2019); disponíveis em língua portuguesa; na íntegra; e no formato original oriundos de produções científicas diversificadas.

Leram-se criticamente, na quarta fase, os resumos dos estudos recuperados, excluindo os duplicados e aqueles cujo ob- 
jetivo, resultados ou conclusão não mencionavam sobre o acesso da criança aos serviços da APS.

Elaborou-se, para facilitar a avaliação e a análise dos dados, um instrumento que pudesse fornecer informações detalhadas dos estudos (Quadro 1). A extração dos dados foi conduzida por dois revisores independentes, sendo que os desacordos entre os revisores em relação aos dados extraídos eram discutidos, tendo como referência a publicação original. Extraíram-se variáveis de identificação tais como: periódico; país e ano de publicação; autor(es); título; delineamento; principais resultados e nível de evidência. Intentou-se com o instrumento, além de formar um banco de dados, mapear pontos pertinentes, integrar dados e caracterizar a amostra revisada.

Apresenta-se a seguir na figura 1 o fluxograma descritor dos resultados obtidos a partir da estratégia de busca de acordo com o fluxograma PRISMA ${ }^{8}$.

Resultou-se a busca na literatura um total de 121 artigos capturados e, desses, 17 estavam no ScIELO, 102 na LILACS e 02 artigos na BDENF. Reduziu-se, a partir da aplicação dos filtros de inclusão, o número de ocorrência: SCIELO, recuperaram-se 07 (29,2\%) estudos; LILACS,
Figura 1 - Fluxograma da seleção dos estudos. Brasília, Distrito Federal, Brasil, 2019.

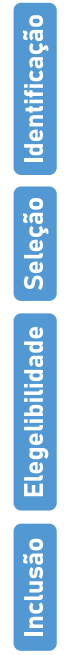

Registros identificados por meio de pesquisas:

SCIELO = 17; LILACS = 102; BDENF $=02(n=121)$

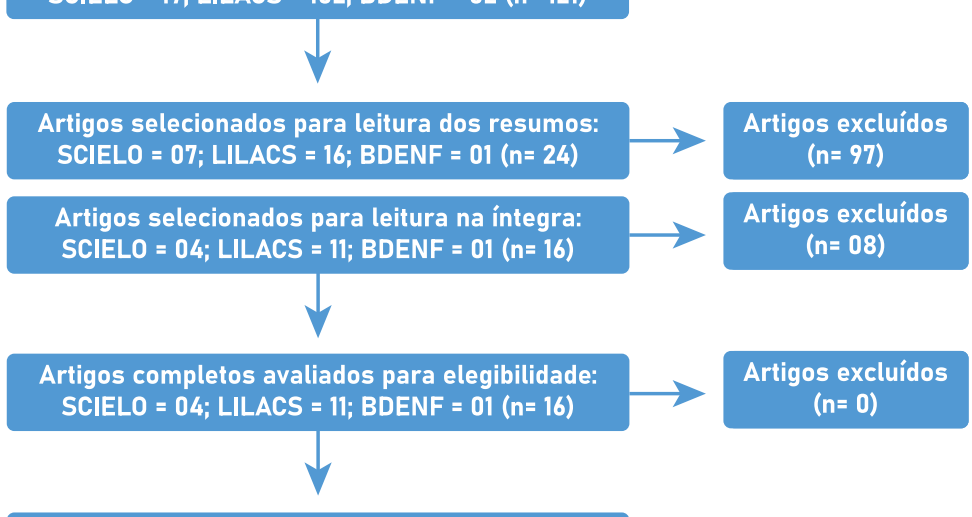

Artigos incluídos em síntese qualitativa e quantitativa $(n=16)$
16 (66,7\%); e BDENF, 01 (4,1\%) estudos. Totalizaram-se 24 artigos submetidos à leitura dos resumos e à aplicação dos critérios de exclusão, gerando-se a rejeição de 97 artigos. Após a leitura completa dos artigos foram rejeitados ainda 08 artigos por não responderam à questão de pesquisa. Constituiu-se assim a amostra revisada de 16 artigos.

Classificaram-se as evidências dos artigos em seis níveis: Nível I - estudos relacionados à metanálise de múltiplos estudos controlados; Nível II - estudos experimentais individuais; Nível III - estudos quase-experimentais, como o ensaio clínico não randomizado, o grupo único pré e pós-teste, além de séries temporais ou caso-controle; Nível IV - estudos não experimentais, como a pesquisa descritiva, correlacional e comparativa, com abordagem qualitativa e estudos de caso; Nível V - dados de avaliação de programas obtidos de forma sistemática; e Nível VI - opinióes de especialistas, relatos de experiência, consensos, regulamentos e legislações?.

\section{RESULTADOS}

Apresenta-se no Quadro 1 a seguir as informações sobre os 16 artigos contidos nesta revisão integrativa. Foram interpretados e sintetizados todos os resultados, através de uma comparação dos dados evidenciados na análise dos artigos.

No que tange ao ano de publicação, foi constatado que a maior quantidade ocor-

Quadro 1 - Distribuição dos artigos de acordo com o periódico, ano de publicação, autor(es), título, delineamento e resultados. Brasilia, Distrito Federal, Brasil, 2020.

\begin{tabular}{|c|c|c|c|c|c|c|}
\hline & $\begin{array}{l}\text { PERIÓDICO, } \\
\text { PAÍS E } \\
\text { ANO DE } \\
\text { PUBLICAÇÃO }\end{array}$ & AUTOR(ES) & TÍTULO & DELINEAMENTO & RESULTADOS & $\begin{array}{l}\text { NIIVEL DE } \\
\text { EVIDÊNCIA }\end{array}$ \\
\hline 总 & $\begin{array}{l}\text { REME Revista } \\
\text { Mineira de } \\
\text { Enfermagem, } \\
\text { Brasil, } 2019\end{array}$ & $\begin{array}{l}\text { Solano LC, } \\
\text { Lacerda VS, } \\
\text { Miranda FN, } \\
\text { Ferreira JKA, } \\
\text { Oliveira } \\
\text { KKD, } \\
\text { Leite AR }\end{array}$ & $\begin{array}{l}\text { Coordenação do } \\
\text { cuidado ao recém- } \\
\text {-nascido prema- } \\
\text { turo: desafios para } \\
\text { atenção primaria à } \\
\text { saúde }\end{array}$ & $\begin{array}{l}\text { Estudo qualitativo } \\
\text { realizado com } 7 \text { coor- } \\
\text { denadores da APS dos } \\
\text { municípios da } 2^{\text {a }} \text { região } \\
\text { de saúde do Estado do } \\
\text { Rio Grande do Norte } \\
\text { (RN). Para análise de da- } \\
\text { dos, utilizou-se a análise } \\
\text { temática de conteúdo. }\end{array}$ & $\begin{array}{l}\text { Os coordenadores expressaram } \\
\text { repertório limitado na produção de } \\
\text { serviços em rede, tendo a APS não } \\
\text { como ordenadora do cuidado, mas } \\
\text { como ponto da rede que atua de } \\
\text { forma reativa, ambulatorial, frag- } \\
\text { mentada, centrada nas doenças } \\
\text { da criança e com frágil apoio das } \\
\text { esferas estadual e federal. }\end{array}$ & IV \\
\hline
\end{tabular}




\section{artigo}

\begin{tabular}{|c|c|c|c|c|c|c|}
\hline $\begin{array}{l}\text { N } \\
0 \\
\text { 兽 } \\
\frac{1}{4}\end{array}$ & $\begin{array}{l}\text { Revista } \\
\text { Rene, Bra- } \\
\text { sil, } 2019\end{array}$ & $\begin{array}{l}\text { Luz RO, } \\
\text { Pieszak GM, } \\
\text { Arrué AM, } \\
\text { Gomes GC, } \\
\text { Neves ET, } \\
\text { Rodrigues } \\
\text { AP }\end{array}$ & $\begin{array}{l}\text { Itinerário terapêu- } \\
\text { tico de familias } \\
\text { de crianças com } \\
\text { necessidades es- } \\
\text { peciais de saúde }\end{array}$ & $\begin{array}{l}\text { Estudo qualitativo realizado no do- } \\
\text { micíio de } 14 \text { familias de crianças } \\
\text { de um município do Rio Grande } \\
\text { do Sul (RS). Utilizou-se para coleta } \\
\text { de dados o instrumento triagem } \\
\text { de crianças com necessidades es- } \\
\text { peciais de saúde, sendo os dados } \\
\text { analisados pela análise temática } \\
\text { de conteúdo. }\end{array}$ & $\begin{array}{l}\text { As familias de crianças com neces- } \\
\text { sidades especiais de saúde sofrem } \\
\text { constantes peregrinações pela rede } \\
\text { de atenção à saúde em busca de as- } \\
\text { sistência e resolutividade. Destaca-se } \\
\text { dificuldades socioeconômicas, fragili- } \\
\text { dades no acesso e vínculo comprome- } \\
\text { tido entre famílias e profissionais. }\end{array}$ & IV \\
\hline 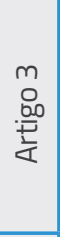 & $\begin{array}{l}\text { Revista de } \\
\text { Enferma- } \\
\text { gem UFPE } \\
\text { Online, } \\
\text { Brasil, } \\
2018\end{array}$ & $\begin{array}{l}\text { Pohin AT, } \\
\text { Gomes } \\
\text { MFP, } \\
\text { Francolli LA] }\end{array}$ & $\begin{array}{l}\text { Estratégia saúde } \\
\text { da família: ótica } \\
\text { dos cuidadores de } \\
\text { crianças }\end{array}$ & $\begin{array}{l}\text { Estudo quantitativo, descritivo } \\
\text { e transversal realizado em } 3 \\
\text { municípios da região de Presidente } \\
\text { Prudente (SP). Utilizou-se o instru- } \\
\text { mento PCATool na versão criança } \\
\text { e adulto. }\end{array}$ & $\begin{array}{l}\text { Os atributos da APS estavam pre- } \\
\text { sentes na ESF da região, porém os } \\
\text { atributos Coordenação do Cuidado, } \\
\text { Acessibilidade e Orientação Familiar } \\
\text { precisavam melhorar sua operacio- } \\
\text { nalização. }\end{array}$ & IV \\
\hline 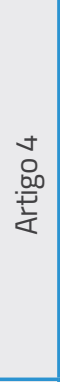 & $\begin{array}{l}\text { Revista } \\
\text { Rene, } \\
\text { Brasil, } \\
2018\end{array}$ & $\begin{array}{l}\text { Benevides } \\
\text { JL, } \\
\text { Gubert FA, } \\
\text { Tomé } \\
\text { MABG, } \\
\text { Vasconce- } \\
\text { los PF, Dodt } \\
\text { RCM, } \\
\text { Pinheiro } \\
\text { SRCS }\end{array}$ & $\begin{array}{l}\text { Atributos da } \\
\text { atenção primária } \\
\text { nas internações de } \\
\text { crianças: acesso de } \\
\text { primeiro contato e } \\
\text { longitudinalidade }\end{array}$ & $\begin{array}{l}\text { Estudo transversal realizado em } \\
2 \text { hospitais pediátricos de uma } \\
\text { capital do Nordeste brasileiro. A } \\
\text { amostra foi de } 120 \text { crianças e a } \\
\text { coleta de dados foi realizada utili- } \\
\text { zando o instrumento PCAToll. }\end{array}$ & $\begin{array}{l}\text { Sob a ótica das mães/cuidadores, } \\
\text { os serviços de APS de modo geral } \\
\text { apresentaram baixa orientação aos } \\
\text { princípios da APS uma vez que os } \\
\text { escores referentes ao atributo Acesso } \\
\text { de primeiro contato e Longitudinalida- } \\
\text { de atingiram escores insatisfatórios }\end{array}$ & IV \\
\hline 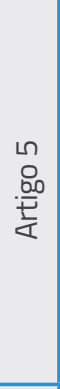 & $\begin{array}{l}\text { Revista } \\
\text { Latino-A- } \\
\text { mericana } \\
\text { de Enfer- } \\
\text { magem, } \\
\text { Brasil, } \\
2018\end{array}$ & $\begin{array}{l}\text { Yakuwa MS, } \\
\text { Neill S, } \\
\text { Mello DF }\end{array}$ & $\begin{array}{l}\text { Estratégias de } \\
\text { enfermeiros para a } \\
\text { vigilância à saúde } \\
\text { da criança }\end{array}$ & $\begin{array}{l}\text { Estudo qualitativo, com análise } \\
\text { temática dos dados. A coleta de } \\
\text { dados foi realizada por meio de } \\
\text { entrevistas semiestruturadas e } \\
\text { na análise dos dados qualitativos, } \\
\text { utilizou-se a análise de conteúdo } \\
\text { do tipo temática indutiva. }\end{array}$ & $\begin{array}{l}\text { A vigilância à saúde da criança exer- } \\
\text { cida pelas enfermeiras vem de certo } \\
\text { modo contribuindo para reduzir vul- } \\
\text { nerabilidades porque têm ações com } \\
\text { as familias, favorecem a capacidade } \\
\text { de respostas de saúde com compar- } \\
\text { tilhamento de saberes, permitem } \\
\text { incremento nos indicadores de saúde } \\
\text { infantil e estreitam relações entre } \\
\text { saúde e direitos da criança. }\end{array}$ & IV \\
\hline 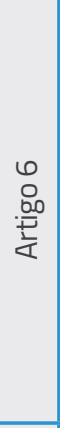 & $\begin{array}{l}\text { Texto \& } \\
\text { Contexto } \\
\text { Enferma- } \\
\text { gem, Brasil, } \\
2018\end{array}$ & $\begin{array}{l}\text { Pinto JTJM, } \\
\text { Freitas } \\
\text { CHSM }\end{array}$ & $\begin{array}{l}\text { Caminhos percor- } \\
\text { ridos por crianças e } \\
\text { adolescentes com } \\
\text { tuberculose nos } \\
\text { serviços de saúde }\end{array}$ & $\begin{array}{l}\text { Estudo exploratório e descritivo } \\
\text { com abordagem qualitativa, rea- } \\
\text { lizado no SINAN de } 2 \text { municípios } \\
\text { do Estado do Rio Grande do Norte } \\
\text { (RN). }\end{array}$ & $\begin{array}{l}\text { A porta de entrada no sistema de saú- } \\
\text { de se deu pelos serviços de urgência e } \\
\text { emergência dos hospitais e das UPA, } \\
\text { sendo que o diagnóstico da tubercu- } \\
\text { lose ocorreu no setor de internação } \\
\text { dos hospitais infantis. A distribuição } \\
\text { e o controle dos medicamentos eram } \\
\text { realizados pelas enfermeiras das UBS. } \\
\text { As consultas médicas eram realiza- } \\
\text { das nos serviços onde foram feitos o } \\
\text { diagnóstico da doença. }\end{array}$ & IV \\
\hline 菙 & $\begin{array}{l}\text { REME } \\
\text { Revista } \\
\text { Mineira de } \\
\text { Enferma- } \\
\text { gem, } \\
\text { Brasil, } \\
2017\end{array}$ & $\begin{array}{l}\text { Dias BE, } \\
\text { Arruda GO, } \\
\text { Marcon SS }\end{array}$ & $\begin{array}{l}\text { Vulnerabilidade } \\
\text { familiar de crianças } \\
\text { com necessida- } \\
\text { des especiais de } \\
\text { cuidados múlti- } \\
\text { plos, complexos e } \\
\text { contínuo }\end{array}$ & $\begin{array}{l}\text { Estudo transversal de abordagem } \\
\text { quantitativa realizado no muni- } \\
\text { cípio de Maringá (PR). A amostra } \\
\text { estudada foi constituída por } 68 \\
\text { crianças e suas familias. }\end{array}$ & $\begin{array}{l}\text { Todas as familias apresentaram-se } \\
\text { vulneráveis, contudo, } 8,8 \% \text { apresen- } \\
\text { taram até } 40 \% \text { de vulnerabilidade. } \\
\text { Identificou-se, ainda, notória vulnera- } \\
\text { bilidade individual devido à fragilidade } \\
\text { clínica da criança, social pela exclu- } \\
\text { são e programática relacionada à } \\
\text { precariedade de acesso aos serviços } \\
\text { de saúde. }\end{array}$ & IV \\
\hline
\end{tabular}




\begin{tabular}{|c|c|c|c|c|c|c|}
\hline 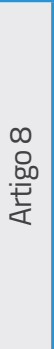 & $\begin{array}{l}\text { Revista } \\
\text { Ciência Plural, } \\
\text { Brasil, } 2017\end{array}$ & $\begin{array}{l}\text { Ferreira } \\
\text { TLS, } \\
\text { Souza AMG, } \\
\text { Medeiros } \\
\text { JSS, } \\
\text { Andrade FB }\end{array}$ & $\begin{array}{l}\text { Avaliação do atri- } \\
\text { buto coordenação } \\
\text { do cuidado em } \\
\text { serviços de pueri- } \\
\text { cultura na atenção } \\
\text { primária à saúde }\end{array}$ & $\begin{array}{l}\text { Estudo exploratório descritivo, } \\
\text { avaliativo e com abordagem quan- } \\
\text { titativa realizado com } 186 \text { pais/ } \\
\text { responsáveis de crianças menores } \\
\text { de } 2 \text { anos de idade da cidade de } \\
\text { Santa Cruz (RN). Para a coleta de } \\
\text { dados foi utilizado o instrumento } \\
\text { PCAToll versão para crianças. }\end{array}$ & $\begin{array}{l}\text { A integração de cuidados apre- } \\
\text { sentou resolutividade das queixas } \\
\text { de } 89,2 \% \text {, uma vez que apenas } \\
10,8 \% \text { foram consultados por } \\
\text { especialistas. Já no que se refere } \\
\text { ao sistema de informações, } 99,5 \% \\
\text { afirmaram disponibilidade dos } \\
\text { registros e boletins de atendi- } \\
\text { mentos durante a consulta. }\end{array}$ & IV \\
\hline $\begin{array}{l}9 \\
0 \\
\text { 感 } \\
\frac{1}{4}\end{array}$ & $\begin{array}{l}\text { Revista da } \\
\text { Escola de } \\
\text { Enfermagem } \\
\text { da USP, } \\
\text { Brasil, } 2017\end{array}$ & $\begin{array}{l}\text { Wolkers } \\
\text { PCB, } \\
\text { Yakuwa MS, } \\
\text { Pancieri L, } \\
\text { Mendes- } \\
\text {-Rodrigues } \\
\text { C, Furtado } \\
\text { MCC, } \\
\text { Mello DF }\end{array}$ & $\begin{array}{l}\text { Crianças com } \\
\text { diabetes mellitus } \\
\text { tipo 1: acesso aos } \\
\text { imunobiológicos } \\
\text { especiais e à pueri- } \\
\text { cultura }\end{array}$ & $\begin{array}{l}\text { Estudo descritivo, transversal } \\
\text { realizado em Uberlândia (MG) com } \\
\text { análise de dados quantitativos a } \\
\text { partir de entrevistas com mães/ } \\
\text { responsáveis de crianças com } \\
\text { DM1. }\end{array}$ & $\begin{array}{l}\text { O estudo apontou fragilidades das } \\
\text { ações de puericultura e vacinação } \\
\text { em crianças com DM1, destacan- } \\
\text { do a baixa cobertura vacinal das } \\
\text { vacinas disponibilizadas pelos } \\
\text { CRIE e lacunas na regularidade } \\
\text { do seguimento em cuidados } \\
\text { primários à saúde, principalmente } \\
\text { em crianças com maior tempo de } \\
\text { diagnóstico de DM1. }\end{array}$ & IV \\
\hline $\begin{array}{l}\text { 음 } \\
0 \\
.00 \\
.00 \\
\frac{1}{2}\end{array}$ & $\begin{array}{l}\text { Semina: } \\
\text { Ciências Bio- } \\
\text { lógicas e da } \\
\text { Saúde, Brasil, } \\
2015\end{array}$ & $\begin{array}{l}\text { Dascheui } \\
\text { JM, } \\
\text { Tacla } \\
\text { MTGM, } \\
\text { Alves BA, } \\
\text { Toso BRGO, } \\
\text { Collet N }\end{array}$ & $\begin{array}{l}\text { Avaliação dos } \\
\text { princípios da } \\
\text { orientação familiar } \\
\text { e comunitária da } \\
\text { atenção primária à } \\
\text { saúde da criança }\end{array}$ & $\begin{array}{l}\text { Estudo descritivo e de natureza } \\
\text { quantitativa que foi realizado em } \\
39 \text { UBS da área urbana do mu- } \\
\text { nicípio de Londrina (PR). Para as } \\
\text { entrevistas, foi utilizado o instru- } \\
\text { mento PCAToll e um questionário } \\
\text { socioeconômico. }\end{array}$ & $\begin{array}{l}\text { O valor do escore para a orien- } \\
\text { tação familiar foi 5,082 e para } \\
\text { orientação comunitária de } 5,462, \\
\text { não atingindo o escore ideal }(6,6) \text {. } \\
\text { Conclui-se então que ambos os } \\
\text { atributos precisam ser desen- } \\
\text { volvidos, com o aperfeiçoamento } \\
\text { ou instalação de novas medidas } \\
\text { que possam ajudar na melhoria } \\
\text { da qualidade da atenção básica à } \\
\text { saúde da criança. }\end{array}$ & IV \\
\hline 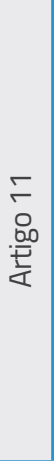 & $\begin{array}{l}\text { Revista } \\
\text { Brasileira de } \\
\text { Saúde Mater- } \\
\text { no-Infantil, } \\
\text { Brasil, } 2015\end{array}$ & $\begin{array}{l}\text { Costa JSD, } \\
\text { Cesar JA, } \\
\text { Weber AP, } \\
\text { Garcez AS, } \\
\text { Nora CRD, } \\
\text { Rower HB, } \\
\text { Kolling V }\end{array}$ & $\begin{array}{l}\text { Características } \\
\text { das crianças } \\
\text { menores de cinco } \\
\text { anos atendidas } \\
\text { em serviços de } \\
\text { atenção básica em } \\
\text { dois municípios do } \\
\text { nordeste brasileiro }\end{array}$ & $\begin{array}{l}\text { Trata-se de estudo transversal de } \\
\text { base populacional com crianças de } \\
\text { O a } 59 \text { meses. A coleta de dados } \\
\text { foi realizada mediante aplicação } \\
\text { de questionários. Utilizou-se para } \\
\text { análise multivariada a Regressão } \\
\text { de Poisson e o modelo hierarqui- } \\
\text { zado. }\end{array}$ & $\begin{array}{l}\text { A prevalência de consultas nos } \\
\text { serviços de saúde em Caracol (PI) } \\
\text { foi de } 44,2 \% \text { e em Anísio de Abreu } \\
\text { (PI) foi de } 48,5 \% \text {. Após ajuste para } \\
\text { eventuais fatores de confusão, } \\
\text { consultar esteve associado com } \\
\text { maior renda familiar e menor } \\
\text { distância do serviço de saúde em } \\
\text { Caracol-PI. Em Anísio de Abreu- } \\
\text {-Pl, o desfecho associou-se com } \\
\text { abastecimento de água e idade } \\
\text { das crianças. }\end{array}$ & IV \\
\hline 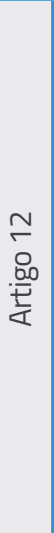 & $\begin{array}{l}\text { Revista da } \\
\text { Escola de En- } \\
\text { fermagem da } \\
\text { USP, Brasil, } \\
2015\end{array}$ & $\begin{array}{l}\text { Oliveira } \\
\text { VBCA, } \\
\text { Verríssimo } \\
\text { MLOR }\end{array}$ & $\begin{array}{l}\text { Assistência à } \\
\text { saúde da criança } \\
\text { segundo suas fa- } \\
\text { mílias: comparação } \\
\text { entre modelos de } \\
\text { Atenção Primária }\end{array}$ & $\begin{array}{l}\text { Estudo transversal, com aborda- } \\
\text { gem quantitativa, realizado com } \\
\text { familiares responsáveis por crian- } \\
\text { ças atendidas no serviço público } \\
\text { de saúde de Colombo (PR), tendo } \\
\text { sido utilizado o PCATool versão } \\
\text { criança. }\end{array}$ & $\begin{array}{l}\text { As unidades com ESF alcançaram } \\
\text { escore geral limítrofe para APS, } \\
\text { porém tiveram melhores resul- } \\
\text { tados nos atributos Coordenação } \\
\text { da integração dos cuidados, } \\
\text { Integralidade, Orientação Familiar } \\
\text { e Acessibilidade. Porém, os } \\
\text { atributos Orientação Comunitária, } \\
\text { Coordenação dos sistemas de } \\
\text { informações, Longitudinalidade e } \\
\text { Acesso foram classificados como } \\
\text { insuficientes para a APS. As UBS } \\
\text { tiveram escores baixos em todos } \\
\text { os atributos. }\end{array}$ & IV \\
\hline
\end{tabular}




\section{artigo}

Ascenso, A.M.R.; Aguiar, R.S.

Acesso da criança na atenção primária à saúde: uma revisão integrativa

\begin{tabular}{|c|c|c|c|c|c|c|}
\hline $\begin{array}{l}m \\
\frac{m}{0} \\
0.00 \\
\frac{10}{1}\end{array}$ & $\begin{array}{l}\text { Revista Lati- } \\
\text { no-Americana } \\
\text { de Enferma- } \\
\text { gem, Brasil, } \\
2015\end{array}$ & $\begin{array}{l}\text { Pina JC, } \\
\text { Moraes SA, } \\
\text { Furtado } \\
\text { MCC, } \\
\text { Mello DF }\end{array}$ & $\begin{array}{l}\text { Presença e exten- } \\
\text { são dos atribu- } \\
\text { tos da atenção } \\
\text { primária à saúde } \\
\text { entre crianças } \\
\text { hospitalizadas por } \\
\text { pneumonia }\end{array}$ & $\begin{array}{l}\text { Estudo observacional, retrospec- } \\
\text { tivo com delineamento caso-con- } \\
\text { trole de base hospitalar realizado } \\
\text { com } 690 \text { crianças menores de } \\
5 \text { anos de idade de } 3 \text { hospitais } \\
\text { conveniados com o SUS de um } \\
\text { município do Estado de São } \\
\text { Paulo (SP), sendo } 345 \text { casos e } 345 \\
\text { controles. }\end{array}$ & $\begin{array}{l}\text { Ambos os grupos apresentaram } \\
\text { escores elevados para acesso } \\
\text { aos serviços de saúde. Diferen- } \\
\text { temente, escores elevados para } \\
\text { atributos como longitudinalidade } \\
\text { e coordenação da atenção se } \\
\text { revelaram nos controles. Apesar } \\
\text { de escores baixos, integralidade } \\
\text { e orientação familiar também } \\
\text { foram maiores para os controles. }\end{array}$ & III \\
\hline 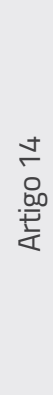 & $\begin{array}{l}\text { Cogitare En- } \\
\text { fermagem, } \\
\text { Brasil, } 2014\end{array}$ & $\begin{array}{l}\text { Fernandes } \\
\text { APP, } \\
\text { Alexandre } \\
\text { AMC, } \\
\text { Dezoti AP, } \\
\text { Mazza VA }\end{array}$ & $\begin{array}{l}\text { A percepção das } \\
\text { familias sobre a } \\
\text { organização da } \\
\text { atenção primária à } \\
\text { saúde da criança }\end{array}$ & $\begin{array}{l}\text { Estudo descritivo com abordagem } \\
\text { qualitativa, realizado em } 3 \text { UBS de } \\
\text { um município da região metropo- } \\
\text { litana de Curitiba (PR). Os dados } \\
\text { foram coletados por meio de } 3 \\
\text { seções de grupos focais, sendo } \\
\text { os dados analisado por meio da } \\
\text { análise temática categorial. }\end{array}$ & $\begin{array}{l}\text { Compreende-se que existem } \\
\text { necessidades de reestruturação } \\
\text { das práticas e organizações dos } \\
\text { serviços de saúde que perpassam } \\
\text { as dimensões locais das UBS. No } \\
\text { entanto, percebe-se o potencial } \\
\text { do acolhimento como uma fer- } \\
\text { ramenta valiosa para minimizar } \\
\text { as insatisfações das familias na } \\
\text { organização dos serviços. }\end{array}$ & IV \\
\hline $\begin{array}{l}\stackrel{10}{5} \\
0 \\
0.00 \\
\frac{.00}{4}\end{array}$ & $\begin{array}{l}\text { Acta Paulista } \\
\text { Enfermagem, } \\
\text { Brasil, } 2014\end{array}$ & $\begin{array}{l}\text { Finkler AL, } \\
\text { Viera CS, } \\
\text { Tacla } \\
\text { MTGM, } \\
\text { Toso BRGO }\end{array}$ & $\begin{array}{l}\text { O acesso e a } \\
\text { dificuldade na } \\
\text { resolutividade do } \\
\text { cuidado da criança } \\
\text { na atenção primá- } \\
\text { ria à saúde }\end{array}$ & $\begin{array}{l}\text { Estudo descritivo de abordagem } \\
\text { qualitativa onde utilizou-se a } \\
\text { hermenêutica para compreensão } \\
\text { dos dados. O instrumento de } \\
\text { pesquisa a técnica de observação } \\
\text { não participante, os dados foram } \\
\text { analisados pelo método da análise } \\
\text { temática. }\end{array}$ & $\begin{array}{l}\text { O acesso ao primeiro contato } \\
\text { demonstrou fragilidades, ficando } \\
\text { evidenciada a existência de bar- } \\
\text { reiras organizacionais. Percebeu- } \\
\text {-se, ainda, um cuidado fragmen- } \\
\text { tado e descoordenado em ambos } \\
\text { os serviços de APS, demonstran- } \\
\text { do que tais serviços carecem de } \\
\text { estruturação e desenvolvimento } \\
\text { de cuidados de saúde resolutivos } \\
\text { para a criança e sua familia. }\end{array}$ & IV \\
\hline 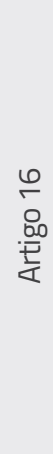 & $\begin{array}{l}\text { Revista } \\
\text { Brasileira de } \\
\text { Enfermagem, } \\
\text { Brasil, } 2014\end{array}$ & $\begin{array}{l}\text { Silva RMM, } \\
\text { Viera CS }\end{array}$ & $\begin{array}{l}\text { Acesso ao cuidado } \\
\text { à saúde da criança } \\
\text { em serviços de } \\
\text { atenção primária }\end{array}$ & $\begin{array}{l}\text { Estudo qualitativo com base no } \\
\text { referencial metodológico da her- } \\
\text { menêutica-dialética. A população } \\
\text { do estudo foi composta por } 16 \\
\text { pessoas atendidas na UPA de } \\
\text { Cascavel (PR). A coleta de dados } \\
\text { foi dividida em três fases: inquérito } \\
\text { domiciliar, Mapas Falantes (MF) e } \\
\text { entrevista semiestruturada. }\end{array}$ & $\begin{array}{l}\text { Foi identificado barreiras ao } \\
\text { acesso principalmente organi- } \\
\text { zacionais e as familias optaram } \\
\text { por inicializar o cuidado em um } \\
\text { serviço considerado não prefe- } \\
\text { rencial - os serviços de urgência } \\
\text { e emergência. Dessa forma, exibi- } \\
\text { ram dificuldades em se alcançar } \\
\text { a resolutividade aos problemas } \\
\text { de saúde dos filhos, pela falta de } \\
\text { continuidade ao cuidado e a não } \\
\text { responsabilização. }\end{array}$ & IV \\
\hline
\end{tabular}

reu nos anos de 2018 e 2015 com quatro artigo cada (25\%), respectivamente. O periódico de maior publicação foi a Revista da Escola de Enfermagem da USP com um total de três artigos (18,7\%). Quanto a região do país em que as pesquisas foram realizadas, seis (37,5\%) foram desenvolvidas na região Nordeste, igual número na re- gião Sul e quatro (25\%) na região Sudeste.

\section{DISCUSSÃO}

A APS deve ser considerada como o primeiro contato dos usuários e de suas famílias com o sistema de saúde, pois conforme se aproxima deles consegue aumentar seu poder de interação e consequentemente uma maior resolutibilidade da atençãó ${ }^{10}$.

Nessa perspectiva, o acompanhamento do crescimento e desenvolvimento infantil se propõe a garantir a saúde integral da criança, sendo responsável pela promoção, prevenção de riscos, agravos e doenças e 
recuperação da saúde, tornando-se eixo fundamental do Sistema Único de Saúde (SUS) por proporcionar acesso às ações programáticas de saúde ${ }^{11}$.

Contudo, sob a ótica das mães e cuidadores os serviços de APS apresentaram baixa orientação aos seus princípios uma vez que os atributos acesso de primeiro contato e longitudinalidade não atingiram os seus objetivos, obtendo resultados insatisfatórios quanto à sua presença e à extensão $0^{12-13}$.

Observa-se ainda que crianças com pais de elevada escolaridade, com fornecimento de luz elétrica, com caderneta de saúde da criança e que a criança havia sido hospitalizada no último ano apresentaram maior prevalência de consulta nos serviços de saúde. Por sua vez, as crianças cujas mães apresentavam 30 anos ou mais, com um número maior de filhos e com idade de até 23 meses consultavam menos nos serviços de saúde revelando, dessa forma, fatores associados que expressavam iniquidade de saúde aos serviços de APS ${ }^{14}$.

Diante disso, as condiçóes socioeconômicas apresentadas pelas famílias, as demandas de cuidados das crianças, a falta de orientação aos pais, o acesso fragilizado e o precário acompanhamento no âmbito da APS representam um conjunto de condições que caracterizam a vulnerabilidade dos indivíduos de forma individual, no contexto social e no programático ${ }^{11}$. Assim, diante desse cenário e mediante a amplitude das barreiras ao acesso, principalmente organizacionais, as famílias muitas vezes optam por iniciar o cuidado pelos serviços de urgência e emergência ${ }^{15}$.

Ademais, evidencia-se que as crianças com condições crônicas, em especial aquelas com necessidades especiais de cuidados múltiplos, complexos e contínuos, estão em situação de vulnerabilidade programática $^{16}$. Assim, a fragilidade na articulação entre os diferentes níveis e locais de prestação de serviços impacta diretamente no retorno da criança ao território e na qualidade da assistência que será prestada a ela e à família, assim como da referência e contrarreferência nos variados graus de complexidade, por vezes ineficaz e pouco empregada ${ }^{17}$.
Diante disso, as condições

\section{socioeconômicas}

apresentadas

pelas famílias,

as demandas de

cuidados das

crianças, a falta de

orientação aos pais,

o acesso fragilizado

e o precário

acompanhamento

no âmbito da

APS representam

um conjunto de

condiçốes que

caracterizam a

vulnerabilidade

dos indivíduos de

forma individual, no

contexto social e no

programático.
Neste contexto, constatou-se ainda que os profissionais de saúde apresentam dificuldades no momento de informar o diagnóstico aos familiares, deixando estes desassistidos e vulneráveis a buscarem orientações sozinhos. Ainda, relatos demonstraram a escassez de credibilidade das famílias para o atendimento das crianças com necessidades especiais de saúde na APS, inclusive evidencia ausência de busca ativa da equipe de saúde em relação à famíliaa ${ }^{18}$.

Por essa e outras razões, as famílias, mesmo com poucos recursos financeiros, consideraram necessário contratar um plano de saúde privado para garantir o acesso aos serviços de saúde das crianças, reforçando a vulnerabilidade das famílias ${ }^{11}$. Diante disso, esse fato deve implicar em um maior protagonismo e responsabilização do setor saúde, bem como a necessidade de repensar e rediscutir ações e políticas públicas, gestão do cuidado em rede, resolutividade da APS e o acesso com vistas ao impacto na qualidade de vida e na redução da morbimortalidade das crianças. ${ }^{19}$ Assim, a oferta de serviços na APS precisa ser aprimorada para cumprir os atributos essenciais e derivados ${ }^{10}$.

Nesse sentido, discute-se problemas no financiamento da APS em nível municipal, tanto pela instabilidade de seus recursos próprios como pelas consequências provenientes da sistemática de incentivos financeiros federais e estaduais à autonomia do sistema de saúde local. Contudo, observa-se que algumas práticas podem ser modificadas, demandando poucos recursos e contribuindo para o alcance dos objetivos dos atributos da APS $^{20}$. Ademais, acrescenta-se limitações relativas ao atendimento da demanda espontânea e à dificuldade para agendamento contribuem para que as crianças não consigam atenção oportuna às suas necessidades de saúde ${ }^{21}$.

Dessa forma, o acesso da criança na APS demonstra fragilidades ficando evidenciada a existência de barreiras organizacionais, impedindo ou dificultando o acesso ao cuidado por meio de dispositivos impostos burocraticamente. Percebe-se, 


\section{artigo}

ainda, um cuidado fragmentado e descoordenado $^{22}$, apontando assim a necessidade de se rediscutir as práticas adotadas de modo a garantir atendimento de qualidade e acesso ao serviço de saúde ${ }^{23}$.

Diante desse cenário, existe a necessidade de se produzir um cuidado centrado na criança a partir de atuação multiprofissional, gerando vínculos, estimulando a autonomia e o protagonismo dos sujeitos envolvidos no processo de trabalho e na superação dos obstáculos existentes no cotidiano colaborativo e coletivo ${ }^{17,24-28}$.

\section{CONCLUSÃO}

Identificou-se barreiras relacionadas ao acesso, principalmente àquelas organizacionais e fragilidades na articulação entre os diferentes níveis e locais de prestação de serviços que impactaram diretamente na atenção à saúde da criança.

Dessa forma, foram encontradas dificuldades em se alcançar a resolutividade dos problemas de saúde da criança pela falta de continuidade do cuidado, demonstrando precariedade na execução de ações e práticas relativas a um olhar ampliado de saúde no momento de entrada do usuário nos serviços em busca de atenção à saúde.

Diante disso, faz-se necessário uma atuação da equipe multiprofissional no âmbito da ESF com a participação ativa do enfermeiro. Além disso, entende-se que precisa existir vínculo empático, longitudinal e integral entre os profissionais de saúde e as famílias. Além disso, considera-se importante investir na formação de profissionais para atuar na APS para que compreendam e efetuem um cuidado centrado na criança e nas famílias.

\section{REFERÊNCIAS}

1. Santos NCCB, Vaz LMC, Nogueira JA, Toso BRGO, Collet N, Reichert APS. Presença e extensão dos atributos de atenção primária à saúde da criança em distintos modelos de cuidado. Cad Saúde Pública. [internet] 2018 [acesso em 2019 Nov 27];34(1):e00014216. Disponivel em: http://www.scielo.br/pdf/ csp/v34n1/1678-4464-csp-34-01-e00014216.pdf doi: https:// doi.org/10.1590/0102-311X00014216

2. Santos DBC, Silva EF, Lima SO, Oliveira CCC. Rede de atenção à saúde: percepção materna quanto à qualidade de atendimento de crianças com microcefalia. Esc Anna Nery Rev Enferm. [internet] 2019 [acesso em 2019 Nov 27];23(4):e20180335. Disponivel em: http://www.scielo.br/scielo.php?pid=S1414-8145 2019000400218\&script=sci_arttext\&tlng=pt doi: https://doi. org/10.1590/2177-9465-EAN-2018-0335

3. Setemba MJ, Simão M, Silva MCM, Scochi CGS, Pina JC, Mello DF. Mortalidade em recém-nascidos de baixo peso ao nascer: limites e desafios para o acesso universal. Port J Public Health. [internet] 2018 [acesso em 2019 Nov 27];36:95-10. Disponivel em: https://www.karger.com/Article/Fulltext/493959 doi: https://doi.org/10.1159/000493959

4. Furtado MCC, Mello DF, Pina JC, Vicente JB, Lima PR, Rezende VD. Ações e articulações do enfermeiro no cuidado da criança na atenção básica. Texto \& Contexto Enferm. [internet] 2018 [acesso em 2019 Nov 27];27(1):e0930016. Disponivel em: http://www. scielo.br/scielo.php?pid=S0104-07072018000100309\&scri pt=sci_abstract\&tlng=pt doi: http://dx.doi.org/10.1590/010407072018000930016

5. Vasconcelos MIO, Xavier ALC, Nascimento MN, Cavalcante YA, Rocha SP, Gomes JS. Avaliação da resolutividade e efetividade da atenção primária à saúde: revisão integrativa de leitura. Sanare (Sobral, Online). [internet] 2018 [acesso em 2019 Nov 27];17(1):65-73. Disponivel em: https://sanare.emnuvens.com. br/sanare/article/view/1224

6. Aguiar RS, Santana DC, Santana PC. A percepção do enfermeiro da estratégia saúde da família sobre a saúde do homem. Rev enferm Cent-Oeste Min. [internet] 2015 [acesso em 2019
Jun 05];5(3):1844-54. Disponivel em: http://www.seer.ufsj. edu.br/index.php/recom/article/view/872 doi: http://dx.doi org/10.19175/recom.v5i3.872

7. Donato $H$, Donato $M$. Etapas na condução de uma revisão sistemática. Acta Med Port [internet] 2019 [acesso em 2019 Set 22];32(3):227-235. Disponivel em: https://www.actamedicaportuguesa.com/revista/index.php/amp/article/view/11923/5635 doi: https://doi.org/10.20344/amp.11923

8. Moher D, Liberati A, Tetzlaff J, Altman DG, The PRISMA Group. Preferred reporting items for systematic reviews and meta-analyses: the PRISMA statement. PLoS Med [internet] 2009 [acesso em 2019 Set 24];6(7):e1000097. Disponível em: www. prisma-statement.org doi: https://doi.org/10.1371/journal. pmed.1000097

9. OCEBM Levels of Evidence Working Group. The Oxford 2011 Levels of Evidence [internet] Oxford: Oxford Centre for Evidence-Based Medicine; 2011 [acesso em 2019 Set 21]. Disponivel em: https://www.cebm.net/2016/05/ocebm-levels-ofevidence/

10. Daschevi JM, Tacla MTGM, Alves BA, Toso BRGO, Collet N. Avaliação dos princípios da orientação familiar e comunitária da atenção primária à saúde da criança. Semina cienc biol saude. [internet] 2015 [acesso em 2019 Set 07];36(1):31-38. Disponivel em: http://www.uel.br/revistas/uel/index.php/seminabio/article/view/18032 doi: https://doi.org/10.5433/16790367.201v36n1p31

11. Ferreira TLS, Souza AMG, Medeiros JSS, Andrade FB. Avaliação do atributo coordenação dos cuidados em serviços de saúde de puericultura na atenção primária à saúde. Rev Ciênc Plur [internet] 2017 [acesso em 2019 Set 06];3(1):98-107. Disponivel em: https://periodicos.ufrn.br/rcp/article/view/12325/8591

12. Benvides JL, Gubert FA, Tomé MABG, Vasconcelos PF, Dodt RCM, Pinheiro SRCS. Atributos da atenção primária nas internações de crianças: acesso de primeiro contato e longitudinalidade. Rev Rene (Online). [internet] 2018 [acesso em 2019 
Set 05];19:e3481. Disponível em: http://periodicos.ufc.br/ rene/article/view/33811 doi: https://doi.org/10.15253/21756783.2018193481

13. Pahim AT, Gomes MFP, Fracolli LA. Estratégia saúde da família: ótica dos cuidadores de crianças. Rev enferm UFPE online. [internet] 2018 [acesso em 2019 Set 05];12(3):607-17. Disponivel em: https://periodicos.ufpe.br/revistas/revistaenfermagem/article/view/24120 doi: https://doi.org/10.5205/19818963-v12i3a24120p607-617-2018

14. Costa JSD, Cesar JA, Weber AP, Garcez AS, Nora CRD, Rower $\mathrm{HB}$ et al. Características das crianças menores de cinco anos atendidas em serviços de atenção básica em dois municípios do nordeste brasileiro. Rev bras saúde mater infant. [internet] 2015 [acesso em 2019 Set 07];15(1):33-46. Disponivel em: http://www.scielo.br/scielo.php?pid=S1519-38292015000100 033\&script=sci_abstract\&tlng=pt doi: https://doi.org/10.1590/ S1519-38292015000100003

15. Silva RMM, Viera CS. Acesso ao cuidado a saúde da criança em serviço de atenção primária. Rev bras enferm. [internet] 2014 [acesso em 2019 Set 08];67(5):794-802. Disponivel em: http://www.scielo.br/scielo.php?script=sci_arttext\&pid=S003471672014000500794\&lng=pt\&tlng=pt doi: https://doi.org/10.1590/0034-7167.2014670518

16. Dias BC, Arruda GO, Marcon SS. Vulnerabilidade familiar de crianças com necessidades especiais de cuidados múltiplos, complexos e contínuo. REME rev min enferm. [internet] 2017 [acesso em 2019 Set 06];21:e1027. Disponivel em: http://www.reme.org.br/artigo/detalhes/1163 doi: https://doi. org/10.5935/1415-2762.20170037

17. Solano LC, Lacerda VS, Miranda FAN, Ferreira JKA, Oliveira KKD, Leite AR. Coordenação do cuidado ao recém-nascido prematuro: desafios para atenção primaria a saúde. REME rev min enferm. [internet] 2019 [acesso em 2019 Set 04];23:e-1168. Disponivel em: http://www.reme.org.br/artigo/detalhes/1311 doi: https://doi.org/10.5935/1415-2762.20190016

18. Luz RO, Pieszak GM, Arrué AM, Gomes GC, Neves ET, Rodrigues AP. Itinerário terapêutico de famílias de crianças com necessidades especiais de saúde. Rev Rene (Online). [internet] 2019 [acesso em 2019 Set 04];20:e33937. Disponível em: http://periodicos.ufc.br/rene/article/view/33937 doi: https://doi. org/10.15253/2175-6783.20192033937

19. Wolkers PCB, Yakuwa MS, Pancieri L, Mendes-Rodrigues C, Furtado MCC, Mello DF. Crianças com diabetes millitus tipo 1: acesso ao imunobiológicos especiais e a puericultura. Rev Esc Enferm USP. [internet] 2017 [acesso em 2019 Set 06];51:e03249. Disponivel em: http://www.scielo.br/scielo.php?pid=S0080-623 42017000100448\&script=sci_arttext\&tlng=pt doi: https://doi. org/10.1590/S1980-220X2016049103249

20. Oliveira VBCA, Veríssimo MLOR. Assistência à saúde da criança segundo suas famílias: composição entre modelos de atenção primária. Rev Esc Enferm USP. [internet] 2015 [acesso em 2019 Set 07];49(1):30-36. Disponível em: http://www.scielo. br/pdf/reeusp/v49n1/pt_0080-6234-reeusp-49-01-0030.pdf doi: https://doi.org/10.1590/S0080-623420150000100004

21. Pina JC, Moraes SA, Furtado MCC, Mello DF. Presença e extensão dos atributos da atenção primária à saúde entre crianças hospitalizadas por pneumonia. Rev latinoam enferm (Online). [internet] 2015 [acesso em 2019 Set 07];23(3):5129. Disponivel em: http://www.scielo.br/scielo.php?script=sci_arttext\&pid=S0104-11692015000300512 doi: https://doi. org/10.1590/0104-1169.0502.2582

22. Finkler AL, Viera CS, Tacla MTGM, Toso BRGO. O acesso e a dificuldade na resolutividade do cuidado da criança na atenção primária à saúde. Acta Paul Enferm (Online). [internet] 2014 [acesso em 2019 Set 08];27(6):548-53. Disponivel em: http://www.scielo.br/scielo.php?script=sci_arttext\&pid=S0103-21002014000600548 doi: http://dx.doi. org/10.1590/1982-0194201400089

23. Yakuwa MS, Neill S, Mello DF. Estratégias de enfermeiros para vigilância à saúde da criança. Rev latinoam enferm (Online). [internet] 2018 [acesso em 2019 Set 05];26:e3007 Disponível em: http://www.scielo.br/pdf/rlae/ v26/pt_0104-1169-rlae-26-e3007.pdf doi: https://doi. org/10.1590/1518-8345.2434.3007

24. Pinto JTJM, Freitas CHSM. Caminhos percorridos por crianças e adolescentes com tuberculose nos serviços de saúde. Texto \& contexto enferm. [Internet] 2018 [acesso em 2019 Set 05];27(1):3880016. Disponivel em: http://www.scielo.br/scielo. php?script=sci_arttext\&pid=S0104-07072018000100324 doi: https://doi.org/10.1590/0104-070720180003880016

25. Fernandes APP, Alexandre AMC, Dezoti AP, Mazza VA. A percepção das famílias sobre a organização da atenção primária a saúde da criança. Cogitare enferm. [internet] 2014 [acesso em 2019 Set 08];19(1):56-62. Disponivel em: https://revistas. ufpr.br/cogitare/article/view/35957/22167 doi: https://doi. org/10.5380/ce.v19i1.35957

26. Lopes IKS, Aguiar RS. Contribuições da enfermagem na prevenção da obesidade infantil: uma revisão integrativa. Research, Society and Development [internet] 2020 [acesso em 2020 Jun 08];9(8):e162985626. Disponivel em: https://rsd.unifei.edu. br/index.php/rsd/article/view/5626/4615 doi: http://dx.doi. org/10.33448/rsd-v9i8.5626

27. Costa VS, Aguiar RS. Percepção da equipe multidisciplinar acerca dos cuidados à criança e ao adolescente vítima de violência. Research, Society and Development [internet] 2020 [acesso em 2020 Jun 08];9(4):e161943038. Disponivel em: https://rsd. unifei.edu.br/index.php/rsd/article/view/3038/2139 doi: http:// dx.doi.org/10.33448/rsd-v9i4.3038

28. Marinho RAQC, Aguiar RS. A atenção primária como eixo estruturante da redução dos indicadores de violência contra crianças e adolescentes. REVISA [internet] 2019 [acesso em 2020 Jun 08];8(2):228-41. Disponivel em: http://revistafacesa.senaaires.com.br/index.php/revisa/article/view/409/302 doi: https:// doi.org/10.36239/revisa.v8.n2.p228a241 